\title{
Mechanics Performances of Different Basalt-Fiber-Reinforced Recycled Aggregate Concretes Subjected to Compression Test
}

\author{
Zhang Xianggang ${ }^{1,2}$, Ding Yahong² and Yang Junna ${ }^{2}$ \\ ${ }^{1}$ Henan Province Engineering Laboratory of Eco-architecture and the Built Environment, Henan Polytechnic University, Jiaozuo \\ 454003, China \\ ${ }^{2}$ School of Civil Engineering, Henan Polytechnic University, Jiaozuo 454003, China
}

Received 4 January 2020; Accepted 29 March 2020

\begin{abstract}
To reveal the mechanical relationship of the compressive strength indexes of two kinds of basalt-fiber-reinforced recycled aggregate concrete (BFRRAC), seven groups of cubic and prismatic standard samples were prepared, respectively. The tests of mechanical properties were carried out under uniaxial compression tests, then the deformation characteristics and failure modes of the two kinds of samples were obtained. The conversion relationships of the compressive strength of two kinds of samples were established. The influences of replacement ratio of recycled coarse aggregate (RRRCA) and basalt fiber content on the elastic modulus were revealed. The function expression of the stressstrain ascending segment and the calculation formula for the elastic modulus of BFRRAC were presented. Results show that with increases of the basalt fiber content, the surface spalling phenomenon of BFRRAC samples becomes less severe. Moreover, the elastic modulus tends to increase. With increase of RRRCA, the elastic modulus of BFRRAC decreases. The obtained conclusions in the study are of important reference value to direct the similar engineering practice.
\end{abstract}

Keywords: BFRRAC, Mechanics performance, Failure mode, RRRCA, Basalt fiber content

\section{Introduction}

At present, the quantity of construction waste in China accounts for 30 to $40 \%$ of municipal waste, of which 50 to $60 \%$ is abandoned concrete [1-2]. Due to the lack of effective treatment for the abandoned concrete, it not only occupies a large amount of land resources but also causes many environmental problems [3-4]. Therefore, the recycling of abandoned concrete is of great significance for protecting the environment, reducing waste of resources and energy, and achieving sustainable development of the construction industry [5-7].

Recycled aggregate concrete (RAC) is a new kind of concrete material which is made by crushing, screening, and washing abandoned concrete, and the purpose is to partly or completely replace natural aggregate [8-9]. RAC plays an important role in recycling construction waste. However, it is affected by the damage caused by recycled coarse aggregate (RCA) during crushing, the residual cement mortar adhered on the surface of RCA, the larger porosity and higher water absorption of RCA, and so on. The mechanical properties of RAC are lower than those of ordinary concrete [10]. A certain amount of basalt fiber (BF) can be incorporated to RAC to prepare BFRRAC. BF has the function of conferring toughening and cracking resistance on the concrete and also has good compatibility with it. Through composite reinforcement with $\mathrm{BF}$, the mechanical and durability properties of RAC are improved, thus promoting the range of utilization of construction waste by recycling.

As an environmentally friendly green building material,

*E-mail address: 2438802458@qq.com

ISSN: 1791-2377 @ 2020 School of Science, IHU. All rights reserved. doi:10.25103/iestr.132.13 the mechanical properties of BFRRAC, especially the deformation properties, need to be studied deeply. However, there are few reports in the relevant literature. Therefore, studies on and application of BFRRAC are still in the initial stage. Satisfyingly, BFRRAC has been proposed and developed on the basis of RAC.

\section{State of the art}

Many researches and reports on the strength and deformation properties of RAC have been published. Within a certain range, engineering pilot applications and development of RAC have also been realized, which has a certain reference and promotion value for the research and application on BFRRAC. Zhu et al. studied the effect of different recycled aggregate contents on the mechanical properties of pervious concrete, and the results show that with increases of the recycled aggregate content, the strength of concrete are decreased [11]. Guo et al. studied the mechanics of concrete blocks containing recycled concrete aggregates, and the results show that the compressive and shear properties of RAC block are similar to those of ordinary concrete block [12]. Deng et al. carried out uniaxial and triaxial tests at different stress ratios and replacement ratios of recycled coarse aggregate, the results show that the strength and deformation of RAC samples are affected by both the RRRCA and the stress ratio [13]. Padmini et al. studied the effect of original concrete on the mechanical properties of RAC, they found that the strength of RAC is related to the strength of the original concrete [14]. Belen et al. show that the longitudinal compression strain of RAC increases with the RRRCA [15]. Chen et al. present that the axial compressive strength of RAC becomes slightly higher 
than that of ordinary concrete as the RRRCA increases, but their complete stress - strain curves have similar shapes [16] Seara-Paz et al. indicate that similarly to short-term deformation properties, RCA deteriorates the long-term deformation properties of RAC [17]. In general, the mentioned research shows that the difference between RAC and ordinary concrete originates from the incorporation and use of recycled aggregate. With increase of the replacement ratio of the recycled aggregate, the strength and deformation of RAC gradually decrease, which is obviously disadvantageous for the further recycling and utilization of construction waste.

Lots of scholars have strengthened the mechanical characteristics of RAC through complex modification with BF. Accordingly, some experiments and analyses on the preparation and mechanical properties of BFRRAC have been carried out. Li et al. tested the compressive strength of BFRRAC samples with different fiber contents, the results show that the compressive strength of BFRRAC increases with increasing BF content [18]. Dong et al. show that BF on the surface of adhered mortar and pore position of coarse aggregate can improve the microstructure of interface transition zone [19]. Zhang et al. carried out impact tests on BFRRAC with various BF volumes and high strain ratios, the interfacial properties and strengthening mechanism of BFRRAC were analyzed and the dynamic constitutive equations of BFRRAC were derived [20]. Katkhuda et al. show that the use of short-cut BF not only increases the compressive strength of RAC, but also significantly increases the bending and splitting tensile strength [21].

The above-mentioned studies mainly focus on enhancement of the strength of RAC by incorporation of BF. The strength and mechanical properties of RAC were improved after BF was incorporated. However, there are few researches on the deformation behavior of BFRRAC including the deformation curve under compression, the elastic modulus, and so on. In view of the shortage of previous research, two kinds of BFRRAC samples were made with varying parameters of RRRCA and BF content. The strength, stress-strain curve, and elastic modulus of BFRRAC were studied systematically. The effects of the BF content and RRRCA on the mechanical properties of BFRRAC were focused to be discussed, which can provide the reference for further research and application of BFRRAC

The rest of this study is organized as follows. Section 3 describes the materials and methods. Section 4 presents the results and discussion, and finally, the conclusions are summarized in Section 5.

\section{Materials and methods}

\subsection{Test materials}

$\mathrm{P} \cdot \mathrm{O}$ 42.5R grade cement was used in this test. The construction waste came from damaged reinforced concrete beams. The strength grade of the original concrete was C25. After manual crushing, screening, cleaning, and grading, the RCA was obtained. Crushed stone was adopted as the natural coarse aggregate and screened under the same conditions as RCA. For both coarse aggregates, the gradation was continuous, and the particle size was 5-31.5 $\mathrm{mm}$. Medium-sized river sand was used, and the mixing water was ordinary tap water. The basic physical properties of both coarse aggregates are shown in Table 1. The water absorption of RCA was much higher than that of natural aggregate and reached up to $5.6 \%$. This is attributed to the porous and rough surface of RCA. The basic properties of $\mathrm{BF}$ are shown in Table 2.

Table 1. Basic physical properties of coarse aggregate.

\begin{tabular}{c|c|c|c|c|c}
\hline Aggregate type & $\begin{array}{c}\text { Grain size } \\
(\mathbf{m m})\end{array}$ & $\begin{array}{c}\text { Bulk density } \\
\left(\mathrm{kg} / \mathrm{m}^{3}\right)\end{array}$ & $\begin{array}{c}\text { Apparent density } \\
\left(\mathrm{kg} / \mathrm{m}^{3}\right)\end{array}$ & $\begin{array}{c}\text { Moisture content } \\
\mathbf{( \% )}\end{array}$ & $\begin{array}{c}\text { Water absorption } \\
\text { ratio } \mathbf{( \% )}\end{array}$ \\
\hline Natural coarse aggregate & $5-31.5$ & 1681 & 2498 & 0 & 0.1 \\
RCA & $5-31.5$ & 1274 & 2196 & 2 & 5.6 \\
\hline
\end{tabular}

Table 2. Properties of BF.

\begin{tabular}{c|c|c|c|c|c}
\hline $\begin{array}{c}\text { Diameter } \\
(\boldsymbol{\mu m})\end{array}$ & $\begin{array}{c}\text { Length } \\
(\mathbf{m m})\end{array}$ & $\begin{array}{c}\text { Density } \\
\left(\mathrm{kg} / \mathrm{m}^{3}\right)\end{array}$ & $\begin{array}{c}\text { Tensile strength } \\
(\mathbf{G P a})\end{array}$ & $\begin{array}{c}\text { Modulus of elasticity } \\
(\mathbf{G P a})\end{array}$ & $\begin{array}{c}\text { Elongation at break } \\
(\mathbf{\%})\end{array}$ \\
\hline 15 & 18 & 2650 & $4.15-4.85$ & $93-115$ & $3.0-3.2$ \\
\hline
\end{tabular}

\subsection{Mix proportions of BFRRAC samples}

Three replacement ratios of recycled coarse aggregates $(\delta, 0$, 50 , and $100 \%)$, three BF contents $\left(m_{\mathrm{BF}}, 0,2\right.$, and $\left.4 \mathrm{~kg} / \mathrm{m}^{3}\right)$, and three test strength grades of RAC (C30, C40, C50) were designed for the preparation of BFRRAC samples. The RRRCA was calculated according to the percentage of RCA in the total coarse aggregate. BF content was the quantity quality of BF incorporated to $1 \mathrm{~m}^{3}$ of BFRRAC. When the BF content was $2 \mathrm{~kg} / \mathrm{m}^{3}$, BFRRAC was defined as the first kind of BFRRAC sample according to the different replacement ratios of recycled coarse aggregate. When the RRRCA was $50 \%$, the prepared BFRRAC was the second kind of BFRRAC sample according to the different BF contents. The fly ash content accounted for $20 \%$ of the cement, and the content of water reducing agent was determined as $0.5 \%$ of the cementitious material. The mixes of RAC are shown in Table 3. Among them, the quantity of additional water was the again-supplemented water, based on the influence of the water absorption ratio of RCA.

\subsection{Two kinds of concrete samples}

Seven groups of $150 \mathrm{~mm} \times 150 \mathrm{~mm} \times 150 \mathrm{~mm}$ cubic samples were designed to measure the cubic compressive strength. Each group contains three duplicate samples. Meanwhile, seven groups of $150 \mathrm{~mm} \times 150 \mathrm{~mm} \times 300 \mathrm{~mm}$ prismatic samples were designed, and each group contained six duplicate samples, of which three prismatic samples were used directly to measure the axial compressive strength and stress-strain complete curves. Longitudinal and transverse strain gages were affixed to the side of the remaining three prismatic samples to measure the elastic modulus.

\subsection{Loading equipments and loading mode}

A microcomputer-controlled electro-hydraulic servo universal testing machine (WAW-2000 type) was adopted to carry out cube and prism compression performance tests. According to China Standard Test Method for Properties of Ordinary Concrete Mixture (GB/T 50080-2002), a mold of 
standard size was selected uniformly to cast BFRRAC samples with different mixes. After 24 hours, the mold was removed and the fresh BFRRAC was cured for 28 days with thin film.

Table 3. Mixes of RAC for three strength grades $\left(\mathrm{kg} / \mathrm{m}^{3}\right)$

\begin{tabular}{c|c|c|c|c|c|c|c|c|c|c|c}
\hline $\begin{array}{c}\text { Strength } \\
\text { grades }\end{array}$ & $\begin{array}{c}\boldsymbol{\delta} \\
\mathbf{( \% )}\end{array}$ & $\begin{array}{c}\text { Water-binder } \\
\text { ratio }\end{array}$ & $\begin{array}{c}\text { Sand ratio } \\
\mathbf{( \% )}\end{array}$ & $\begin{array}{c}\text { Net water } \\
\text { content }\end{array}$ & $\begin{array}{c}\text { Additional water } \\
\text { content }\end{array}$ & Cement & Fly ash & RCA & $\begin{array}{c}\text { Natural coarse } \\
\text { aggregate }\end{array}$ & Sand & $\begin{array}{c}\text { Water } \\
\text { reducer }\end{array}$ \\
\hline C40 & 0 & 0.40 & 31 & 205 & 0.0 & 430 & 86 & 0.0 & 1115.2 \\
C40 & 50 & 0.40 & 31 & 205 & 31.2 & 430 & 86 & 557.6 & 557.6 & 2.58 \\
C40 & 100 & 0.40 & 31 & 205 & 62.5 & 430 & 86 & 1115.2 & 0.0 & 501 \\
C30 & 50 & 0.50 & 32 & 210 & 33.7 & 350 & 70 & 602.5 & 602.5 \\
C50 & 50 & 0.35 & 34 & 185 & 32.8 & 435 & 87 & 586.5 & 586 \\
\hline
\end{tabular}

In accordance with China Standard for Test Method of Mechanical Properties on Ordinary Concrete (GB/T 500812002), the test block was preloaded one to three times to balance the contact before the test block was formally loaded Load was applied uniformly and continuously at a rate of 0.5 $\mathrm{MPa} / \mathrm{s}$ until the test block was destroyed, and the data of the compressive strength, stress, and elastic modulus were collected automatically by computer. The strain value was collected by strain gages connected with an uT7116 static strain gauge.

\section{Results and analysis}

\subsection{Failure modes of different samples}

4.1.1 Failure characteristics under cube compression test At the beginning of loading, there were no visible cracks in the cube samples. With increases in the load, the stress in the samples gradually increased, and occasionally a weak colloid-cracking sound appeared. When the load increased to the peak point, in the middle of the sample, there were one or several cracks parallel to the longitudinal direction. With increases of the load, the crack extended obliquely, and the angle with the horizontal direction was about $45^{\circ}$. Meanwhile, BFRRAC gradually peeled off, exhibiting a four-angle cone failure mode which was connected upside down. The typical failure modes of the samples are shown in Fig. 1. It can be seen that the failure modes of all BFRRAC samples are basically the same.

\subsubsection{Failure characteristics under axial compression test} At the beginning of loading, the surface of the BFRRAC prismatic sample had no obvious change. When the load increased, similarly to cube compression, occasionally a weak colloid-cracking sound occurred. After that, a few vertical micro-cracks appeared in the middle of the sample. With continuous increases of the load, micro-cracks developed and connected with each other steadily, forming the main oblique cracks. After the peak load, the main oblique crack penetrated the whole cross-section of the sample, and brittle failure occurred in the prismatic sample because of the spalling of the block. The failure modes of typical prismatic samples are presented in Fig. 2.

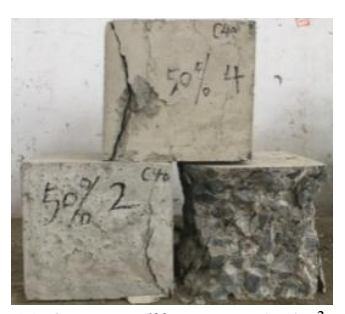

(a) $\delta=50 \% m_{\mathrm{BF}}=0-4 \mathrm{~kg} / \mathrm{m}^{3}$

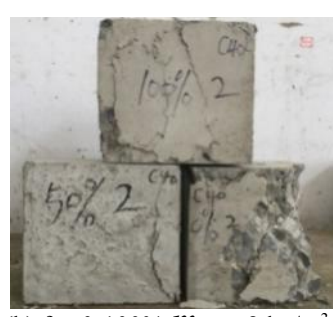

(b) $\delta=0-100 \% m_{\mathrm{BF}}=2 \mathrm{~kg} / \mathrm{m}^{3}$

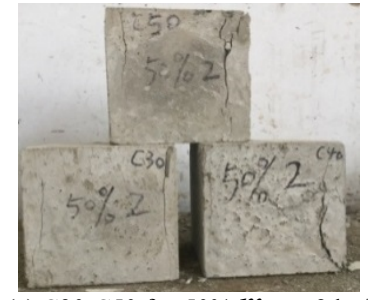

(c) $\mathrm{C} 30-\mathrm{C} 50 \delta=50 \% m_{\mathrm{BF}}=2 \mathrm{~kg} / \mathrm{m}^{3}$

Fig. 1. Typical failure modes of BFRRAC cubic test samples.

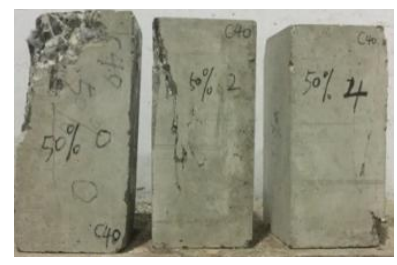

(a) $\delta=50 \% m_{\mathrm{BF}}=0-4 \mathrm{~kg} / \mathrm{m}^{3}$

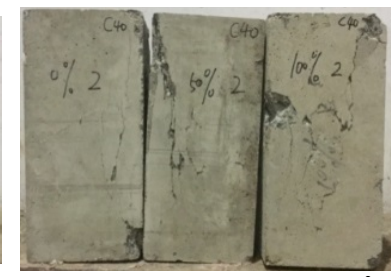

(b) $\delta=0-100 \% m_{\mathrm{BF}}=2 \mathrm{~kg} / \mathrm{m}^{3}$

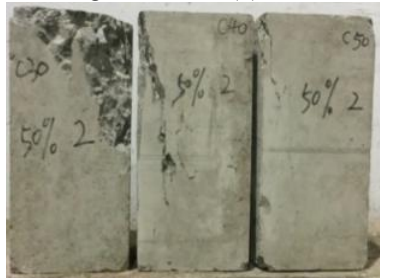

(c) $\mathrm{C} 30-\mathrm{C} 50 \delta=50 \% m_{\mathrm{BF}}=2 \mathrm{~kg} / \mathrm{m}^{3}$

Fig. 2. Typical failure modes of BFRRAC prismatic test samples.

Both Figs. 1(a) and 2(a) indicate that when the replacement ratio was $50 \%$ and the fiber content was 0 $\mathrm{kg} / \mathrm{m}^{3}$, the surface spalling of BFRRAC cubic and prismatic samples was severe. With increases of the BF content, the spalling phenomenon on the surface of the sample became less severe. When the BF content reached $4 \mathrm{~kg} / \mathrm{m}^{3}$, the BFRRAC on the sample surface did not peel off and only the main oblique cracks appeared. This is because in the process of cubic and prismatic compression of the BFRRAC sample, the $\mathrm{BF}$ played the role of bridging. In other words, the appearance and development of oblique cracks in the sample was restrained well by the BF effect of toughening and cracking-inhibition. Macroscopically, the samples showed strong overall performance and did not disperse and fracture under external load.

4.2 Influencing factors of compressive strength and strength index conversion relationships

In accordance with the China Test Method for Mechanical Properties of Ordinary Concrete (GB50081-2002), the cubic compressive strength and axial compressive strength of BFRRAC were measured, as shown in Table 4. It was found that the cubic compressive strength of BFRRAC samples reached the requirements of the design strength grades; 
furthermore, the compressive strength of BFRRAC was closely related to the RRRCA and BF content.

Table 4. Measured strength indexes of BFRRAC

\begin{tabular}{c|c|c|c}
\hline Sample number & $\left.f_{\mathrm{cu}} \mathbf{( M P a}\right)$ & $f_{\mathrm{c}} \mathbf{( M P a )}$ & $f_{\mathrm{c}} / f_{\mathrm{cu}}$ \\
\hline C40-0-2 & 48.4 & 37.2 & 0.77 \\
C40-50-2 & 46.5 & 33.5 & 0.72 \\
C40-100-2 & 43.7 & 30.6 & 0.70 \\
C40-50-0 & 45.3 & 33.1 & 0.73 \\
C40-50-4 & 47.2 & 35.8 & 0.76 \\
C30-50-2 & 37.1 & 27.5 & 0.74 \\
C50-50-2 & 54.6 & 43.1 & 0.79 \\
\hline
\end{tabular}

Note: $f_{\text {cu }}$ and $f_{\mathrm{c}}$ stand for cubic compressive strength and axial compressive strength, respectively. The $\mathrm{C} 40$ in $\mathrm{C} 40-0-2$ represents the BFRRAC strength grade. " 0 " indicates a replacement ratio of $0 \%$. " 2 " refers to a BF content of $2 \mathrm{~kg} / \mathrm{m}^{3}$. The meanings of the other numbers are similar to the above description.

\subsubsection{Replacement ratio of recycled coarse aggregate}

From Table 4, it can be seen that the compressive strength of BFRRAC decreased with increases in the RRRCA. This is because natural damage to the original concrete in the process of stress, and the additional damage implemented by the original concrete crushing, caused the interior of the RCA to accumulate a large number of cracks and microcracks. At the same time, a lot of coarse cement mortar was attached to the surface of RCA, resulting in high porosity and an uncompacted interface. The higher the RRRCA, the more significant the adverse effects on the BFRRAC, therefore, the lower its cubic compressive strength and axial compressive strength.

When the BF content was $2 \mathrm{~kg} / \mathrm{m}^{3}$, the linear relation between the cubic compressive strength and RRRCA of the BFRRAC was significant. The compressive strength decreased by 3.93 and $6.02 \%$ respectively with increases of the replacement ratio. Based on the change law, the linear dimensionless function expressions are proposed.

Eq. (1) shows the relational expression of dimensionless cubic compressive strength for the first kind of BFRRAC sample when $m_{\mathrm{BF}}=2 \mathrm{~kg} / \mathrm{m}^{3}$.

$$
f_{\mathrm{cu}, \mathrm{R}} / f_{\mathrm{cu}, 0}=-0.0097 \delta+1.0031 \quad 0 \leq \delta \leq 1 \quad R^{2}=0.98
$$

where $f_{\mathrm{cu}, \mathrm{R}}$ is the cubic compressive strength of the BFRRAC sample at different replacement ratios when $m_{\mathrm{BF}}=2 \mathrm{~kg} / \mathrm{m}^{3}$, $f_{\mathrm{cu}, 0}$ is the cubic compressive strength of the BFRRAC sample when $m_{\mathrm{BF}}=2 \mathrm{~kg} / \mathrm{m}^{3}$ and $\delta=0 \%$.

Similarly to the cubic compressive strength, a uniform change rule was also presented between the axial compressive strength of BFRRAC and the RRRCA. When the BF content was $2 \mathrm{~kg} / \mathrm{m}^{3}$, the axial compressive strength of BFRRAC decreased by 9.95 and $8.66 \%$, respectively, with increases of the replacement ratio.

Eq. (2) shows the relational expression of dimensionless axial compressive strength for the first kind of BFRRAC sample when $m_{\mathrm{BF}}=2 \mathrm{~kg} / \mathrm{m}^{3}$.

$$
f_{\mathrm{c}, \mathrm{R}} / f_{\mathrm{c}, 0}=-0.1880 \delta+0.9981 \quad 0 \leq \delta \leq 1 \quad R^{2}=1.00
$$

where $f_{\mathrm{c}, \mathrm{R}}$ is the axial compressive strength of the BFRRAC sample at different replacement ratios when $m_{\mathrm{BF}}=2 \mathrm{~kg} / \mathrm{m}^{3}$, $f_{\mathrm{c}, 0}$ is the axial compressive strength of the BFRRAC sample when $m_{\mathrm{BF}}=2 \mathrm{~kg} / \mathrm{m}^{3}$ and $\delta=0 \%$.

\subsubsection{BF content}

From Table 4, it can be observed that the compressive strength of BFRRAC increased gradually with increases of the $\mathrm{BF}$ content. This is because, according to material mechanics, under uniaxial compression, the failure of concrete sample is attributed not to compression but to the crack parallel to the loading direction, which causes tensile breaking of the sample. Nevertheless, the BF plays the role of bridging in the BFRRAC sample, which restrains the appearance and development of internal micro-cracks and cracks to some extent. Therefore, BF can enhance the cubic compressive strength and axial compressive strength of BFRRAC.

When the RRRCA was $50 \%$, the cubic compressive strength of the BFRRAC increased by 2.65 and $1.51 \%$, respectively, with changes of the BF content, respectively. Moreover, the cubic compressive strength of BFRRAC generally showed a linear relation with the BF content.

Eq. (3) shows the relational expression of dimensionless cubic compressive strength for the second kind of BFRRAC sample when $\delta=50 \%$.

$$
f_{\mathrm{cu}, \mathrm{R}} / f_{\mathrm{cu}, 0}=0.0105 m_{\mathrm{BF}}+1.0018 \quad 0 \leq m_{\mathrm{BF}} \leq 4 \quad R^{2}=0.96
$$

When the RRRCA was $50 \%$, the relationship between the axial compressive strength of BFRRAC $\left(f_{\mathrm{c}}\right)$ and the content of $\mathrm{BF}\left(m_{\mathrm{BF}}\right)$ was basically linear, and the variation amplitude of $f_{\mathrm{c}}$ was 1.21 and $7.16 \%$ with changes of $m_{\mathrm{BF}}$, respectively.

Eq. (4) shows the relational expression of dimensionless axial compressive strength for the second kind of BFRRAC sample when $\delta=50 \%$.

$$
f_{\mathrm{c}, \mathrm{R}} / f_{\mathrm{c}, 0}=0.0212 m_{\mathrm{BF}}+0.9900 \quad 0 \leq m_{\mathrm{BF}} \leq 4 \quad R^{2}=0.94
$$

\subsubsection{Conversion relationships of compressive strength indexes for different samples}

For ordinary concrete, the conversion ratio between axial compressive strength and cubic compressive strength is 0.76 [22].

From Table 4 , it can be shown that $f_{\mathrm{c}} / f_{\text {cu }}$ of BFRRAC is related to the RRRCA and BF content. A linear function is used to fit the mathematical expression, as shown in Eqs. (5) and (6). With increases of the RRRCA, $f_{\mathrm{c}} / f_{\text {cu }}$ showed a decreasing trend, and the variation amplitude was 6.50 and $0.28 \%$, respectively. As the $\mathrm{BF}$ content increased, $f_{\mathrm{c}} / f_{\mathrm{cu}}$ showed a linear increasing trend with increases of the BF content, and its variation amplitude was $1.39 \%$ and $4.11 \%$, respectively.

Eq. (5) gives the conversion relationship of the compressive strength for the first kind of BFRRAC sample when $m_{\mathrm{BF}}=2 \mathrm{~kg} / \mathrm{m}^{3}$.

$$
f_{\mathrm{c}} / f_{\text {cu }}=-0.0700 \delta+0.7650 \quad 0 \leq \delta \leq 1 \quad R^{2}=0.88
$$

Eq. (6) gives the formula for conversion of compressive strength for the second kind of BFRRAC sample when $\delta=$ $50 \%$.

$$
f_{\mathrm{c}} / f_{\mathrm{cu}}=0.0075 m_{\mathrm{BF}}+0.7270 \quad 0 \leq m_{\mathrm{BF}} \leq 4 \quad R^{2}=0.83
$$

\subsection{Calculation formulas of elastic modulus}

As one of the important indexes for material deformation performance, many experts and scholars have performed experiments and analyses on the elastic modulus of RAC 
$[23,24]$. However, there are few reports on the elastic modulus of BFRRAC. Based on China Code for the Design of Concrete Structures (GB/T50010-2010), the calculation formula of the elastic modulus for ordinary concrete can be presented.

The secant modulus from the origin to $0.4 f_{\mathrm{c}}$ on stressstrain curve is regarded as the measured values of elastic modulus for BFRRAC. The calculated value of BFRRAC modulus can be obtained from the measured cubic compressive strength listed in Table 4 , which is calculated by China GB/T50010-2010. The calculated values of elastic modulus of BFRRAC are presented in Table 5.

Table 5. The calculated and measured values of the elastic modulus of BFRRAC.

\begin{tabular}{c|c|c|c}
\hline Table 5. The calculated and measured values of the elastic modulus of BFRRAC. & $E_{\mathrm{c}}^{\mathrm{t}} \mathbf{( G P a )}$ & $E_{\mathrm{c}}^{\mathrm{c}} / E_{\mathrm{c}}^{\mathrm{t}}$ \\
\hline Sample number & $E_{\mathrm{c}}^{\mathrm{c}}(\mathbf{G P a})$ & 28.60 & 1.20 \\
C40-0-2 & 34.35 & 23.25 & 1.46 \\
C40-50-2 & 33.94 & 18.31 & 1.99 \\
C40-100-2 & 33.40 & 23.38 & 1.84 \\
C40-50-0 & 33.72 & 18.20 & 1.46 \\
C30-50-4 & 34.25 & 29.50 & 1.75 \\
C50-50-2 & 31.89 & 35.27 & 1.20 \\
\hline
\end{tabular}

It can be seen From Table 5 that: (1) At the same BF content $\left(2 \mathrm{~kg} / \mathrm{m}^{3}\right)$, the measured elastic modulus of BFRRAC (C40) generally showed a decreasing rule with increases of the replacement ratio, and the decrease amplitude was 18.71 and $27.74 \%$, respectively. This is because the elastic modulus of BFRRAC is weakened by inferior factors such as the larger porosity, lower bulk and apparent density of RCA compared to natural aggregate as well as congenital fine cracks. (2) At the same replacement ratio $(50 \%)$, the measured elastic modulus of BFRRAC (C40) showed a small increase with increases of BF content, and the increase amplitude was 0.65 and $0.91 \%$, respectively. It is shown that to a certain extent, $\mathrm{BF}$ inhibits the occurrence and development of cracks, thereby improving the ability of BFRRAC to resist deformation. (3) When $m_{\mathrm{BF}}=2 \mathrm{~kg} / \mathrm{m}^{3}$, the measured values $E_{\mathrm{c}}^{\mathrm{t}}$ of elastic modulus for BFRRAC were all lower than the calculated values $E_{\mathrm{c}}^{\mathrm{c}}$ at different replacement ratios. It can be shown that the current China Code for Design of Concrete Structures (GB/T50010-2010) is no longer applicable to the calculation of the elastic modulus of BFRRAC, which is considered as a new type of concrete.

Therefore, a linear function is adopted to modify the formula in GB/T50010-2010, based on the change trend between $E_{\mathrm{c}}^{\mathrm{c}} / E_{\mathrm{c}}^{\mathrm{t}}$ and $\delta$, between $E_{\mathrm{c}}^{\mathrm{c}} / E_{\mathrm{c}}^{\mathrm{t}}$ and $m_{\mathrm{BF}}$. The mathematical expressions for the elastic modulus of BFRRAC at $m_{\mathrm{BF}}=2 \mathrm{~kg} / \mathrm{m}^{3}$, different replacement ratios of recycled coarse aggregate, and $\delta=50 \%$, different fiber contents were established, as shown in Eqs. (7) and (8), respectively.

Eq. (7) gives the calculation method of the elastic modulus of the first kind of BFRRAC sample when $m_{\mathrm{BF}}=2$ $\mathrm{kg} / \mathrm{m}^{3}$.

$$
E_{\mathrm{c}}=\frac{10^{5}}{2.2+\frac{34.7}{f_{\mathrm{cu}}}}(-0.3316 \delta+0.8267) \quad R^{2}=0.99
$$

Eq. (8) gives the calculation method of the elastic modulus of the second kind of BFRRAC sample when $\delta=$ $50 \%$.

$$
E_{\mathrm{c}}=\frac{10^{5}}{2.2+\frac{34.7}{f_{\mathrm{cu}}}}\left(0.0013 m_{\mathrm{BF}}+0.9990\right) \quad R^{2}=0.92
$$

\subsection{Variation characteristics of stress-strain curves}

Based on the measured load of the BFRRAC subjected to axial compression, the stress $(\sigma)$ of the sample during axial compression was calculated, and the strain $(\varepsilon)$ was measured by the strain gage. Because the descending section curve measured by the strain gage was discrete. Moreover, part of the descending section curve was incomplete. Thus only the ascending segment of the curve was analyzed. As shown in Fig. 3, the ascending segment curve was made from the mean of the compression curves of three prisms.

It can be seen from Fig. 3 that the replacement ratio has a great effect on the stress-strain curve of BFRRAC at the same fiber content, regardless of the similar development tendency among ascending segments. With increases of the replacement ratio, the curves of the compressive ascending segment for BFRRAC become more and more inclined to the horizontal coordinate axis; that is, the curve slopes decrease gradually. At the same replacement ratio, the ascending segment curves of BFRRAC at different fiber contents deviated little, and the curve characteristics were not distinct from each other.

According to the measured stress-strain curves of BFRRAC under axial compression, the dimensionless analysis was carried out. Then the constitutive equation model [25] can be used to fit the ascending segment curve, as shown in Eq. (9).

$$
y=a x+(3-2 a) x^{2}+(a-2) x^{3} \quad 0 \leq x \leq 1
$$

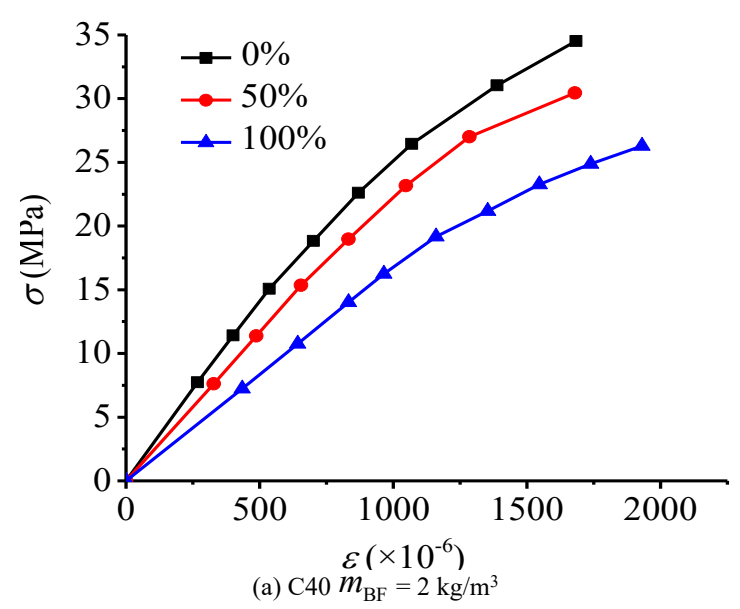




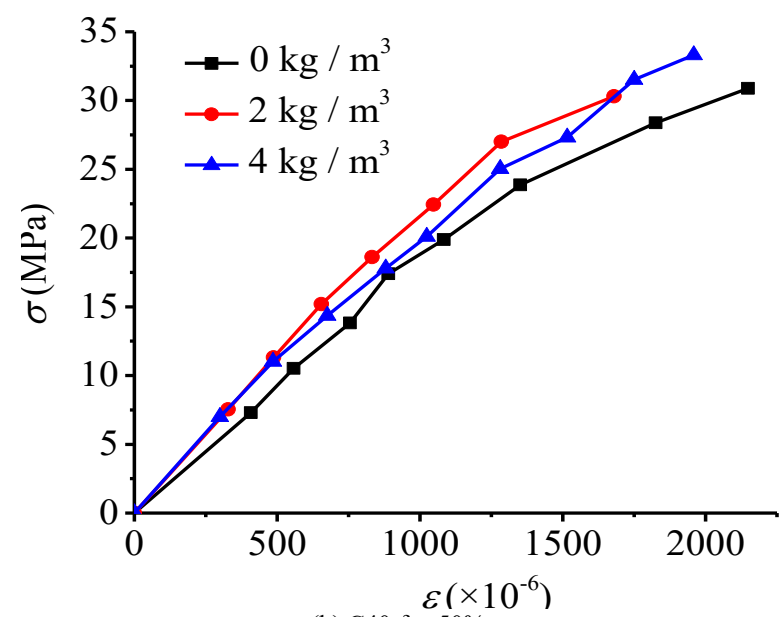

(b) $\mathrm{C} 40 \delta=50 \%$

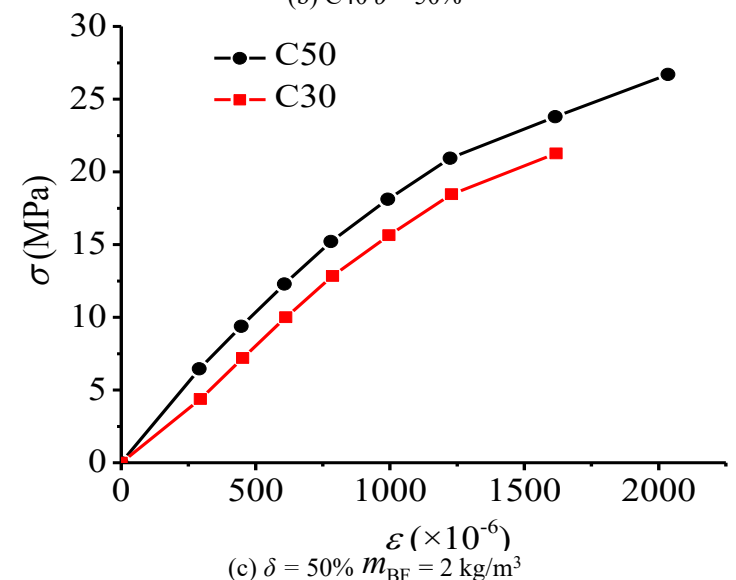

Fig. 3. Ascending segment curve of stress versus strain for BFRRAC

According to the principle of the least squares method, the measured data were fitted and analyzed. The values of undetermined parameters $a$ at different $\mathrm{BF}$ contents and replacement ratios of recycled coarse aggregate were calculated. Based on the value of $a$, it can be found that at the same $\mathrm{BF}$ content, the value of $a$ decreases gradually with increases of the replacement ratio, which indicates that the modulus of elasticity of BFRRAC decreases gradually. After statistical regression, the relationships between the parameter $a$ and the replacement ratio $\delta$ and $\mathrm{BF}$ content $m_{\mathrm{BF}}$ were established, as shown in Eqs. (10) and (11), respectively.

Eq. (10) shows the calculation method of the parameter $a$ for the first kind of BFRRAC sample when $m_{\mathrm{BF}}=2$ $\mathrm{kg} / \mathrm{m}^{3}$.

$$
a=1.08 \delta^{2}-1.72 \delta+1.70 \quad 0 \leq x \leq 1 \quad R^{2}=0.99
$$

Eq. (11) shows the calculation method of the parameter $a$ for the second kind of the BFRRAC sample when $\delta=$ $50 \%$.

$$
a=0.02 m_{\mathrm{BF}}^{2}-0.15 m_{\mathrm{BF}}+1.33 \quad 0 \leq m_{\mathrm{BF}} \leq 4 \quad R^{2}=0.98
$$

When $m_{\mathrm{BF}}=2 \mathrm{~kg} / \mathrm{m}^{3}$, considering two cases of $\delta=0$ and $100 \%$, the value of $a$ could be obtained by Eq. (10) and was then plugged into Eq. (9), so the calculated BFRRAC stress-strain curve under uniaxial compression could be presented. Moreover, the calculated curves were compared with the measured curves, as shown in Fig. 4, where $\sigma_{\mathrm{c}}$ and $\varepsilon_{\mathrm{c}}$ stand for peak stress and peak strain, respectively. It can be seen that the two kinds of curves agreed well with each other.

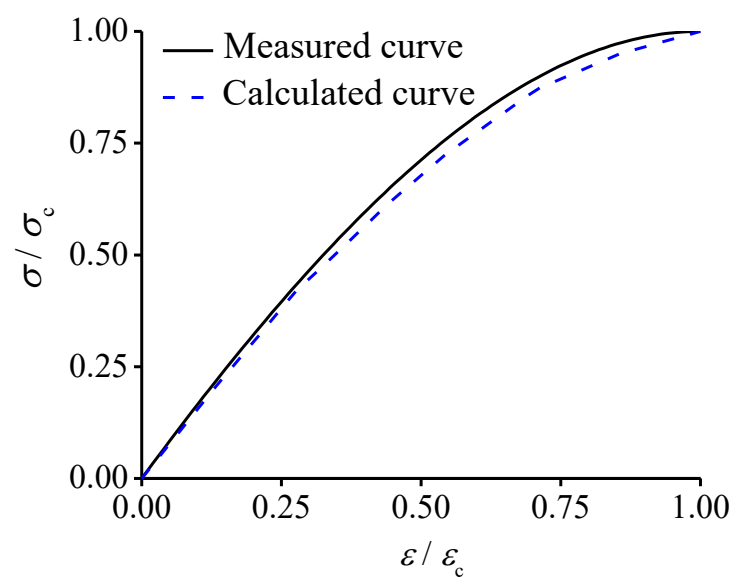

(a) $\delta=0 \%$

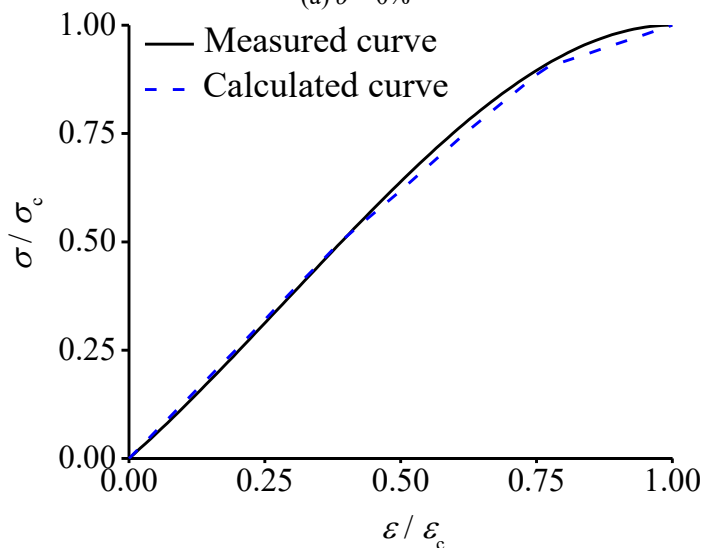

(b) $\delta=100 \%$

Fig. 4. Comparison of measured and calculated stress-strain curves for BFRRAC when $m_{\mathrm{BF}}=2 \mathrm{~kg} / \mathrm{m}^{3}$

\section{Conclusions}

Based on the experimental data, the mechanical properties including the compressive strength, elastic modulus, and stress-strain curve were analyzed for two kinds of BFRRAC samples with different replacement ratios of recycled coarse aggregate and basalt fiber contents. The main conclusions are as follows:

(1) With increases of the basalt fiber content, the surface spalling phenomenon of BFRRAC compressive cube and prism samples becomes less severe. The cube sample shows a four-angle cone failure mode which is connected upside down. The prismatic sample is destroyed by the main oblique crack.

(2) When the basalt fiber content is constant, the elastic modulus of BFRRAC decreases gradually with increases of the RRRCA. Conversely, when the RRRCA is constant, the elastic modulus of BFRRAC tends to increase gradually with increases of the basalt fiber content.

(3) The conversion formula of compressive strength for normal concrete no longer applies to BFRRAC. A simple and practical conversion formula between the axial compressive strength and cubic compressive strength for two kinds of BFRRAC samples is established.

(4) For two kinds of BFRRAC samples with different replacement ratios of recycled coarse aggregate and basalt fiber contents, the mathematical expressions for the elastic modulus and compressive ascending segment curves of stress versus strain are established, and the calculated results are in good agreement with the measured results. 


\section{Acknowledgement}

This work was financially supported by the National Natural Science Foundation of China (51774112, 51474188), the Doctoral Fund of Henan Polytechnic University (B2015-67), Taihang Scholars Program, Key Scientific Research Project Plan for Colleges and Universities in Henan Province (20A560012) and the Young Backbone Teachers Funding
Scheme of Henan Polytechnic University (2019XQG-15). All these are gratefully appreciated.

This is an Open Access article distributed under the terms of the Creative Commons Attribution License

\section{References}

1. Gholampour, A., Ozbakkaloglu, T. "Time-dependent and long-term mechanical properties of concretes incorporating different grades of coarse recycled concrete aggregates". Engineering Structures, 157, 2017, pp. 224-234.

2. Gonzalez-Fonteboa, B., Seara-Paz, S., de Brito, J., GonzalezTaboada, I., Martinez-Abella, F., Vasco-Silva, R. "Recycled concrete with coarse recycled aggregate. An overview and analysis". Materiales De Construccion, 68(30), 2018, UNSP e151.

3. Aslani, F., Ma, G. W., Wan, D. L. Y., Muselin, G. "Development of high-performance self- compacting concrete using waste recycled concrete aggregates and rubber granules". Journal of Cleaner Production, 182, 2018, pp. 553-566.

4. Bovea, M. D., Powell, J. C. "Developments in life cycle assessment applied to evaluate the environmental performance of construction and demolition wastes". Waste Management, 50, 2016, pp. 151-172.

5. Behera, M., Bhattacharyya, S. K., Minocha, A. K., Deoliya, R., Maiti, S. "Recycled aggregate from C\&D waste \& its use in concrete-A breakthrough towards sustainability in construction sector: A review". Construction and Building Materials, 68, 2014, pp. 501516.

6. Bostanci, S. C, Limbachiya, M., Kew, H. "Use of recycled aggregates for low carbon and cost effective concrete construction". Journal of Cleaner Production, 189, 2018, pp. $176-196$.

7. Zhang, X. G., Kuang, X. M., Yang, J. H., Wang, S. R. "Experimental study on mechanical properties of lightweight concrete with shale aggregate replaced partially by nature sand". Electronic Journal of Structural Engineering, 17(1), 2017, pp. 85-94.

8. Casuccio, M., Torrijos, M. C., Giaccio, G., Zerbino, R. "Failure mechanism of recycled aggregate concrete". Construction and Building Materials, 22(7), 2007, pp. 1500-1506.

9. Meng, Y. Z., Ling, T. C., Mo, K. H. "Recycling of wastes for valueadded applications in concrete blocks: An overview". Resources Conservation and Recycling, 138, 2018, pp. 298-312.

10. Cantero, B., del Bosque, I. F. S., Matias, A., Medina, C. "Statistically significant effects of mixed recycled aggregate on the physical- mechanical properties of structural concretes". Construction and Building Materials, 185, 2018, pp. 93- 101.

11. Zhu, X. Y., Chen, X. D., Shen, N., Tian, H. X., Fan, X. Q., Lu, J. "Mechanical properties of pervious concrete with recycled aggregate". Computers and Concrete, 21(6), 2018, pp. 623-635.

12. Guo, Z. G., Tu, A., Chen, C., Lehman, D. E. "Mechanical properties, durability, and life- cycle assessment of concrete building blocks incorporating recycled concrete aggregates". Journal of Cleaner Production, 199, 2018, pp. 136-149.

13. Deng, Z. H., Wang, Y. M., Sheng, J., Hu, X. "Strength and deformation of recycled aggregate concrete under triaxial compression". Construction and Building Materials, 156, 2017, pp. 1043-1052.
14. Padmini, A. K., Ramamurthy, K., Mathews, M. S. "Influence of parent concrete on the properties of recycled aggregate concrete". Construction and Building Materials, 23(2), 2009, pp. 829-836.

15. Belen, G. F., Fernando, M. A., Diego, C. L., Sindy, S. P. "Stressstrain relationship in axial compression for concrete using recycled saturated coarse aggregate". Construction and Building Materials, 25(5), 2011, pp. 2335-2342.

16. Chen, Z. P., Xu, J. J., Zheng, H. H., Su, Y. S., Xue, Y. J., Li, J. T. "Basic mechanical properties test and stress-strain constitutive relations of recycled coarse aggregate concrete". Journal of Building Materials, 16(1), 2013, pp. 24-32.

17. Seara-Paz, S., Gonzalez-Fonteboa, B., Martinez-Abella, F., CarroLopez, D. "Long-term flexural performance of reinforced concrete beams with recycled coarse aggregates". Construction and Building Materials, 176, 2018, pp. 593-607.

18. Li, S. J. "Experimental study of compressive strength of basalt fiber recycled aggregate concrete". World Earthquake Engineering. 32(2), 2016, pp. 89-92.

19. Dong, J. F., Wang, Q. Y., Guan, Z. W. "Material properties of basalt fibre reinforced concrete made with recycled earthquake waste". Construction and Building Materials. 130, 2017, pp. 241- 251.

20. Zhang, H., Wang, B., Xie, A. Y., Qi, Y. Z. "Experimental study on dynamic mechanical properties and constitutive model of basalt fiber reinforced concrete". Construction and Building Materials, 152, 2017, pp. $154-167$.

21. Katkhuda, H., Shatarat, N. "Improving the mechanical properties of recycled concrete aggregate using chopped basalt fibers and acid treatment". Construction and Building Materials. 140, 2017, pp. 328-335.

22. Zhang, X. G., Deng, D. P., Yang, J. H. "Mechanical properties and conversion relations of strength indexes for stone/sand-lightweight aggregate concrete". Advances in Materials Science and Engineering, 2018, 2018, pp. 5402953.

23. Silva, R. V., de Brito, J., Dhir, R. K. "Establishing a relationship between modulus of elasticity and compressive strength of recycled aggregate concrete". Journal of Cleaner Production, 112, 2016, pp. 2171-2186.

24. Golafshani, E. M., Behnood, A. "Automatic regression methods for formulation of elastic modulus of recycled aggregate concrete". Applied Soft Computing, 64, 2018, pp. 377-400.

25. Guo, Z. H., Guo, Y. T., Xu, Y., Ye, X. G., Li, W. Z. “A nonlinear orthotropic constitutive model for concrete". Journal of Tsinghua University (Science and Technology), 37(6), 1997, pp. 78-81. 